ISSN 0021-8944, Journal of Applied Mechanics and Technical Physics, 2019, Vol. 60, No. 1, p. 186. (C) Pleiades Publishing, Ltd., 2019.

Original Russian Text (C) V.A. Il'in, L.A. Ponomareva.

\title{
ERRATUM TO: THE MODEL OF ELECTRIC CONNECTION OF A LOW-CONDUCTIVITY LIQUID IN HIGH-FREQUENCY ELECTRIC FIELD
}

\author{
V. A. Il'in and L. A. Ponomareva
}

DOI: $10.1134 /$ S002189441901022X

In the original publication, there are several misprints.

1. In page header, the author's name was misspelled. It should read "Ponomareva" instead of "Ponomarev."

2. In title, it should read "The Model of Electric Convection of a Low-Conductivity Liquid in High-Frequency Electric Field" instead of "The Model of Electric Connection of a Low-Conductivity Liquid in High-Frequency Electric Field."

The online version of the original article can be found at https://doi.org/10.1134/S0021894418020025.

Perm State University, Perm, 614990 Russia; ilin1@psu.ru; sushi-08@mail.ru. Translated from Prikladnaya Mekhanika i Tekhnicheskaya Fizika, Vol. 59, No. 2, pp. 12-22, March-April, 2018. Original article submitted July 9, 2015; revision submitted May 12, 2017. 